\title{
Does Magnesium Deficient Diet and its Associated Metabolic Dysfunctions Induces Anxiety-like Symptoms Further cardiovascular relevance
}

\begin{abstract}
CRISTIAN STATESCU ${ }^{1}$, CEZAR HONCERIU ${ }^{2 *}$, CONSTANTIN TRUS ${ }^{3}$
${ }^{1}$ Grigore T.Popa University of Medicine and Pharmacy, 16 Universitatii Str., 700115, Iasi, Romania

${ }^{2}$ Alexandru loan Cuza University, 11 Carol I, Blvd., 700506, lasi, Romania

${ }^{3}$ Dunarea de Jos University, Faculty of Medicine, Department of Morphological and Functional Sciences, 47 Domneasca Str., 800008, Galati, Romania

Zinc ions are considered to be one of the most abundant trace elements in the human body. Among many important functions, zinc ions regulate the function of numerous structural, transcriptional and enzymatic proteins that play important roles in the correct function of the central nervous system. Thus, in the present work we were interested in determining some preliminary relevance for the possible effect of acute zinc administration on the anxiety-like behavior. Our initial results described here are showing interesting biotechnological relevance for zinc in this anxiety-related context and also further theoretical developing on this area considering oxidative stress related mechanisms. Moreover, the cardiovascular relevance in both contexts of magnesium vs. cardiovascular effects or anxiety and its relations with the cardiovascular system are presented.
\end{abstract}

Keywords: magnesium, anxiety, oxidative stress, cardiovascular

Anxiety is a psychological disorder and is characterized by apprehensive expectation or uncontrollably fears [1]. The available international data suggest that the lifetime prevalence of any anxiety disorder is approximately one in three, more than any other psychiatric disorders [2]. The main symptoms of anxiety can be, either affective (fear, apprehension) or physiological (racing heart, trembling).

However, the diagnosis of anxiety can be problematic because there are many variables that should be taken in to consideration. These variables include the frequency and severity of the symptoms as well as whether triggers for these symptoms are specific or more generalized [3]. Anxiety importance in the medical health care comes from the fact that it represents a risk factor for lower quality of life [4], increased risk of all-cause mortality [5] and a variety of physical health problems, particularly cardiovascular problems. Furthermore, high levels of anxiety have also been positively correlated with an increased risk of hypertension [6], heart disease [7] and with an increased probability of developing a form of cancer [8].

Anxiety has been extensively studied using animal models and ithas been defined as negative emotional states induced by the presence of a threat or the anticipation of one [9]. Hence, anxiety allows animals to prepare coping with a potentially dangerous situation. Anxiety tests using laboratory rodents, especially the open field test became fundamental tools in the quest of developing pharmaceutical treatments. The open field test is usually applied in laboratory rodents. The strength of this model comes from its simplicity. The open field test makes use of the animals' natural aversion for unfamiliar open space to induce anxiety-like symptoms [10]. The simplicity of the apparatus needed for this animal model has certainly contributed to its popularity [11].

The validity and reliability of the open field test comes from numerous pharmacological and cross-study validations [11-13]. The majority of the available literature that use the open field test comes from drug screening studies, where the use of anxiolytic substances leads to a decrease in the occurrence of anxiety-like behaviors [1419].

Regarding the magnesium and the anxiety in animal models a causal relationship is suggested. Rats with low plasma magnesium levels were found to display increased anxiety- related behavior. This causal relationship was found to be unrelated of whether the depleted levels of magnesium are natural or experimentally induced [20-21].

In addition, some studies have showed that supplementing with magnesium reduces the anxiety-like behavior of rats in different animal models [22]. Furthermore, stimulated by these results, some authors have recently suggested that hypomagnesaemia may even be a possible biomarker of anxiety [20].

\section{Experimental part}

Methods

Our sample consisted of 40 Wistar rats (180-220 g), which were randomly assigned to two groups: the control group and the magnesium deficient group. Rats assigned to magnesium deficient group were allowed to freely access a $0.005 \%$ magnesium containing diet which provided about $10 \%$ of the daily magnesium requirement $[21,23]$. Control rats were fed a normal, $0.2 \%$ magnesium containing diet which offers four times more than the minimum magnesium requirement [23].

Rats were left undisturbed in their home cages for two weeks from the start of diet until the start of behavioral experiments. After animals had been habituated to the testing room for at least $24 \mathrm{~h}$, behavioral experiments were carried out between 09:00 $\mathrm{h}$ and 14:00 $\mathrm{h}$. Testing chambers were carefully cleaned with tap water and a damp towel after each animal had been tested.

The open field test consisted of a plastic box $(42 \times 42 \times 42 \mathrm{~cm})$. The area of the open field, illuminated with 150 lux, was divided into a $28 \times 28 \mathrm{~cm}$ central zone and a surrounding border zone. Mice were placed individually into the periphery of the open field and allowed to explore it for $10 \mathrm{~min}$. The following anxiety-related

* email: chonceri@yahoo.fr 
parameter was recorded: entries into the central zone, time spent in the central zone.

Romanian and the European laws on animal use in biomedical research were considered in animal care and experimental procedures. All efforts were made in order to reduce animal suffering.

\section{Results and discussions}

The statistical analysis of our data showed that there was a statistically significant difference between the control group and the group that received a magnesium deficient diet for 2 weeks regarding the time in the center of the Open Field Test, $F(1, .38)=447.550, p<0.001$.

The differences were in the sense that the rats in the control group spent significantly more time in the center of the Open Test Field ( with a mean of 88.60 seconds, SD = 5.471) compared with the rats which received a magnesium deficient diet for 2 weeks (mean of 50.20 seconds, SD = 5.996).

In the present study we have shown that dietary magnesium restriction enhanced anxiety-related behavior in rats. These data support a relationship between low magnesium levels and anxiety-related behavior in rats. Specifically, we compared a control group with an experimental group regarding the anxiety- like behavior in the open field test. The difference between the control group and the experimental group was the diet of the rodents. Rats assigned to magnesium deficient group were allowed to freely access a $0.005 \%$ magnesium containing diet which provided about $10 \%$ of the daily magnesium requirement. On the other hand the rats in the control group were fed a normal, $0.2 \%$ magnesium containing diet which offers four times more than the minimum magnesium requirement. Our statistical analysis showed that after two weeks of a magnesium deficient diet, the rats in the control group spent significantly more time in the center of the open field compared to the control rats. The findings in the present study are in line with those found in the literature $[21,24]$.

For example, in a study which also used the open field test, rodents which were fed a magnesium deficient diet also presented an increased anxiety-like behavior [24]. In addition to experimentally reducing plasma magnesium levels by feeding the rodents a low in magnesium diet, studies have also used rodents' strains that present natural low levels of magnesium. The results of these studies showed that these strains, which naturally have a lower level of magnesium in their bodies have also been

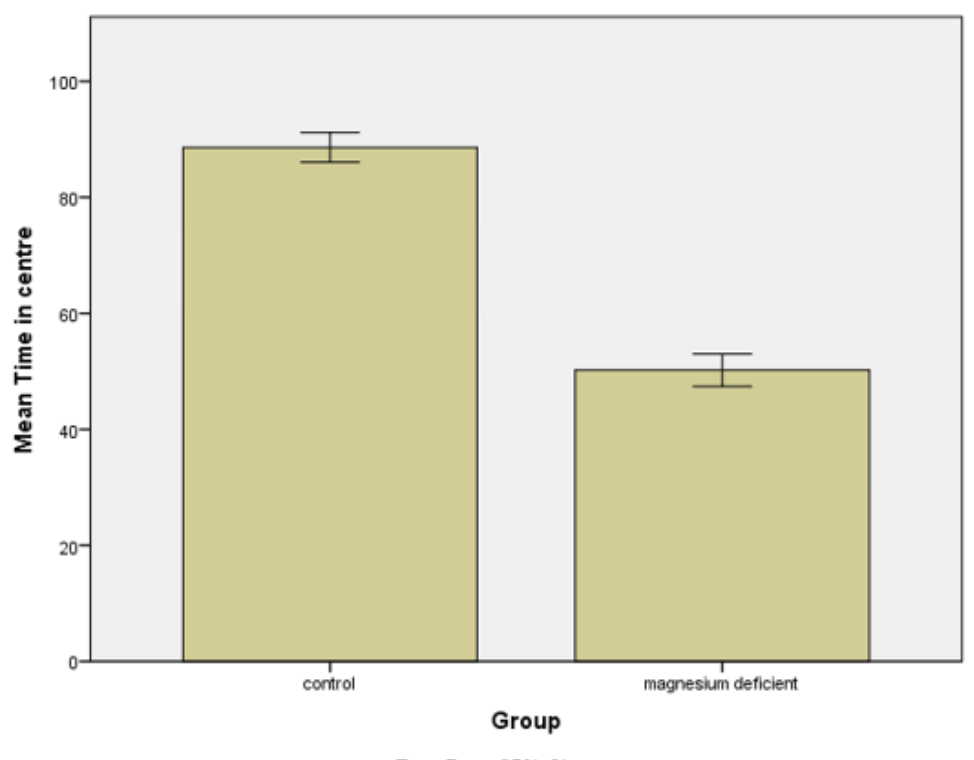

correlated with a statistically significant increase of anxietylike behaviors [20].

In regards to the exact biomolecular mechanism through which magnesium influences the levels of anxiety, several theories have been proposed. Therefore, in the search for neurobiological mechanisms underlying abnormal anxiety, some authors have speculated that magnesium plays an important role because it is one of the essential ions in the brain and it is known for affecting many intracellular processes. To be more specific, it has been demonstrated in the literature that magnesium modulates the glutamatergic neurotransmission [25]. Furthermore, another intracellular in which magnesium is involved is the GABA neurotransmission. It has also been demonstrated that magnesium modulates the GABA neurotransmission and also affects numerous transduction pathways, including that of protein kinase C [26].

Another theory on how magnesium may modulate the level of anxiety is based on the idea that it has been shown that magnesium controls the activity of the hypothalamicpituitary adrenocortical axis [27]. The hypothalamicpituitary adrenocortical axis is considered to be the main stress response system [28]. Therefore, it has been speculated that magnesium modulates the anxiety through a better response system. In addition, ithas been suggested that a disorder in the hypothalamic-pituitary adrenocortical axis system may be one of the main factors of pathological anxiety [28-30].

Lastly, anxiety-like behavior is known to be regulated by other various neurotransmitter systems in the amygdala and other parts of the limbic system. We previously illustrated the glutamatergic and GABA neurotransmission. However it has also been demonstrated that non-NMDA receptors also contribute to synaptic transmission during anxiety-like behaviors in the basolateral nuclei of the amygdala [31]. Furthermore, ithas been demonstrated that the NMDA receptor antagonists also produces significant anxiolytic effects in various animal models of anxiety, such as the open field test and the elevated plus maze [32].

The results of the present study results emphasize the hypothesized, and possibly causal, association between magnesium and anxiety-like behaviors. In our sample of rats, a two weeks diet which was deficient in magnesium produced more anxiety related behaviors in the open field test compared to a diet with a normal level of magnesium.

Moreover, the data we presented here can exhibit a significant importance in the cardiovascular bigger context

Fig 1. The differences between the control group and the group that received a magnesium deficient diet regarding the time in center in the Open Field test 
of magnesium vs. cardiovascular effects or anxiety and its relations with the cardiovascular system.

In this way, it was previously showed for example in a complex systematic review from 2018 by Nuria et al [33] group that magnesium supplementation is generally associated with a decreased risk of another related major cardiovascular risk factors such as diabetes, hypertension, metabolic syndrome and even stroke, while on the other side very high levels of circulating magnesium can be generally associated with a decreased risk of ischemic heart disease and coronary heart disease. Moreover similar individual studies from 2006 [34] or more recent ones [35] suggested a positive effect in general for the magnesium supplementation vs. cardiovascular effects context.

Same goes for the connections that might exist between anxiety and the cardiovascular system, with recent papers from 2017 for example by the Celano et al [36] group suggesting that anxiety could act as a biomarker in this context, and treatment it, could be fundamental for the cardiovascular risk itself. Thus, the mecanistical explanations for this matter could be represented mainly by autonomic dysfunction, inflammation, endothelial dysfunction, changes in platelet aggregation [36]. Again, some other authors included in 2016 anxiety as a clear risk factor for the cardiovascular diseases [37], with other reports suggesting similar aspects even from 1986 [38].

\section{Conclusions}

We are showing here some preliminary relevance for the possible effect of acute zinc administration on the anxiety-like behavior. Moreover, the cardiovascular relevance in both contexts of magnesium vs. cardiovascular effects or anxiety and its relations with the cardiovascular system were broadly presented.

\section{References}

1.*** Diagnostic and Statistical Manual of Mental Disorders: DSM-5. American Psychiatric Association; Washington, DC, 2013.

2. KESSLER, R.C., PETUKHOVA, M., SAMPSON, N.A., ZASLAVSKY, A.M., WITTCHEN, H.-U., International Journal of Methods in Psychiatric Research, 21, no. 3, 2012, p. 169.

3. HALLER, H., CRAMER, H., LAUCHE, R., GASS, F., DOBOS, G., BMC Psychiatry, 14, 2014, Article no. 128.

4. STEIN, M.B., ROY-BYRNE, P.P., CRASKE, M.G., et al., Medical Care, 43, no.12, 2005, p. 1164.

5. TOLMUNEN, T., LEHTO, S.M., JULKUNEN, J., HINTIKKA, J., KAUHANEN, J., Annals of Epidemiology, 24, no. 6, 2014, p. 463.

6. MARKOVITZ, J.H., MATTHEWS, K.A., KANNEL, W.B., COBB, J.L., D'AGOSTINO, R.B., J ournal of the American Medical Association, 270, no. 20, 1993, p. 2439.

7. KAWACHI, I., SPARROW, D., VOKONAS, P.S., WEISS, S.T., Circulation, 1994, 90, p. 2225.

8. MCCARRON, P., GUNNELL, D., HARRISON, G.L., OKASHA, M., DAVEY SMITH, G., J ournal of Epidemiology and Community Health, 57, no. 11,2003, p. 888 .
9. ENNACEUR, A., Physiology Behavior, 135, 2014, p. 55.

10. ARCHER J., Life Science, 43, 1981, p. 20.

11. WALSH, R.N., CUMMINS, R.A., Psychol Bull, 83, 1976, p. 482.

12. DEPINO, A.M., GROSS, C., Behavioural Brain Research, 177, no. 2, 2007, p. 254.

13. PAUL, E.S., HARDING, E.J ., MENDL, M., Neuroscience Biobehavioral Reviews, 29, no. 3, 2005, p. 469.

14. FILE, S.E., Behavioral Brain Research, 125, no. 1-2, 2001, p. 151. 15. TREIT, D., Neuroscience Biobehavioral Reviews, 9, no. 2, 1985, p. 203.

16. PELLOW, S., CHOPIN, P., FILE, S.E., BRILEY, M., J ournal of Neuroscience Methods, 14, no. 3, 1985, p. 149.

17. CAROBREZ, A.P., BERTOGLIO, L.J., Neuroscience and Biobehavioral Reviews, 29, no. 8, 2005, p. 1193.

18. CHOLERIS, E., THOMAS, A.W., KAVALIERS, M., PRATO, F.S., Neurosci Biobehav Rev., 25, no. 3, 2001, p. 235.

19. PAWLAK, C.R., KARRENBAUER, B.D., SCHNEIDER, P., HO, Y.J ., Emotion Review, 4, no. 1, 2012, p. 98.

20. LAARAKKER, M.C., VAN LITH, H.A., OHL, F., Physiol. Behavior, 102, no. 2, 2011, p. 205.

21. SINGEWALD, N., SINNER, C., HETZENAUER, A., SARTORI, S.B., MURCK, H., Neuropharmacology 47, 2004, p. 1189.

22. POLESZAK, E., SZEWCZYK, B., KEDZIERSKA, E., WLAZ, P., PILC, A., NOWAK, G., Pharmacol. Biochem. Behav., 78, no. 1, 2004, p. 7.

23. KANTAK, K.M.. Behav. Neuroscience, 102, no. 2, 1988, p. 304.

24. MUROYAMA, A., INAKA, M., MATSUSHIMA, H., SUGINO, H., MARUNAKA, Y., MITSUMOTO, Y., Neurosci. Research, 63, no. 1, 2009, p. 72.

25. HADDAD, J.J., Prog. Neurobiology, 77, 2005, p. 252.

26. MURCK, H., Nutritional Neuroscience, 5, no. 6, 2002, p. 375.

27. MURCK, H., STEIGER, A., Psychopharmacology (Berl.) 137, 1998, p. 247.

28. YOUNG, E.A., ABELSON, J.L., LIBERZON, I., Stress hormones and anxiety disorders.In: Blanchard, R.J., Blanchard, D.C., Griebel, G., Nutt, D. (Eds.), Handbook of Anxiety and Fear. Academic Press, Oxford, 2008, p. 455.

29. CHARNEY, D.S., DREVETS, W.C., Neurobiological basis of anxiety disorders. In: Davis, K.L., Charney, D., Coyle, J.T., Nemeroff, C. (Eds.), Neuropsychopharmacology e 5th Generation of Progress., 2008, American College of Neuropsychopharmacology, Nashville.

30. MILLAN, M.J., Progress in Neurobiology, 70, no. 2, 2003, p. 83.

31. LEDOUX, J.E., Annual Review Neuroscience, 23, 2000, p. 155.

32. MARTINEZ, G., ROPERO, C., FUNES, A., FLORES, E., BLOTTA, C., LANDA, A.I. et al., Physiology Behavior, 76, no. 2, 2002, p. 219.

33. ROSIQUE-ESTEBAN, N, GUASCH-FERRE, M, HERNANDEZ-ALONSO, P., SALAS-SALVADO, J., Nutrients. 10, no. 2, 2018, p. 168.

34. EFSTRATIADIS, G., SARIGIANNI, M., GOUGOURELAS, I., Hippokratia, 10, no. 4, 2006, p. 147.

35. DINICOLANTONIO, J. J., LIU, J., O'KEEFE, J.H., Open Heart, 5, no. 2, 2018, UNSP e000775.

36. CELANO, C.M., DAUNIS, D.J ., LOKKO, H.N., CAMPBELL, K.A., HUFFMAN, J.C., Current Psychiatry Reports, 18, no. 11, 2016, p. 101. 37. OUAKININ, S.R., Front Psychiatry, 7, 2016, p. 25. doi:10.3389/ fpsyt.2016.00025

38. ROSENMAN, R.H., Psychosomatics, 26, no. 11 Suppl, 1985, p. 6. 